\title{
THE DEVELOPMENT OF A MANAGEMENT ERROR ORIENTATION QUESTIONNAIRE
}

\author{
VICTOR A KORSTEN \\ KAREL J STANZ \\ J BLIGNAUT \\ Programme in Leadership in Performance and Change \\ Department of Human Resources \\ Rand Afrikaans University \\ kst@eb.rau.ac.za
}

\begin{abstract}
The aim of this study was to develop a Management Error Orientation Questionnaire (MEOQ) to be used as an instrument to measure the attitude of management towards errors in the workplace. The sample comprised of 232 managers from a variety of business sectors. A factor analysis on 59 items yielded three factors and these factors were interpreted as the attitude of dealing with errors, the risk of errors and error strain. The three scales were subjected to an item analysis and yielded significant levels of reliability.
\end{abstract}

\section{OPSOMMIMG}

Die doel van die studie was om 'n Bestuursfout Oriëntasie Vraelys (Management Error Orientation Questionniare) te ontwikkel wat as ' $n$ meetinstrument kan dien om die houding van bestuur met betrekking tot foute, in die werksomgewing te bepaal. Die steekproef het uit 232 bestuurders uit 'n verskeidenheid van besigheidsektore bestaan. 'n Faktoranalise op 59 items het drie faktore opgelewer, naamlik die houding aangaande die hantering van foute, die risiko van foute en foutspanning. Die drie faktore is onderwerp aan 'n itemanalise en het aanvaarbare vlakke van betroubaarheid gelewer.

The last two decades constituted a period of great discovery and change for business in the global environment. The fall of communism, the development of international trade unions over continents, new political dispensations, the social responsibilities of a world in which poverty increases, international health threats and trade treaties across international borders, has opened new frontiers in management thinking. The knowledge, skills and leadership qualities that managers and leaders need in the new business environment, differ significantly from what they were during times of stability.

The re-admission of South Africa into the global arena has an impact on South Africa business leaders and the decisions they make regarding their competitive advantage. Huysamen (2002) indicate that the business leaders in South Africa faces the following major challenges: the growing impact of Aids on the community; growing urbanisation; low literacy rate of the South African workforce; resource shortages; crime in the business environment; involvement of government in the business sector and the huge amount of unutilised potential in the country and in business.

Human action played a major role in a large number of spectacular incidents and accidents - and in an even larger number of seemingly mundane events. From the literature it appears that work related errors and their consequences could be disastrous. Not only to the individual or those closely involved in the error situation but, due to the scale and nature of the technology, also to society at large - at times regardless of national borders. In this regard reference has been made to the Tenerife runway collision (1977), the Three Mile Island nuclear accident (1979), the Bhopal tragedy (1984), the Challenger and Chernobyl disasters (1986), the loss of the Mars Orbiter (1999), the Concorde crash (2000) and the Enron (2001) and Saambou Bank liquidations (2002).

From this list and other incidents cited in the literature, it seems reasonable to suggest that errors can occur in all human or human initiated activities - whether it be in transport, the nuclear field, mining, advertising or finance. The implication is that errors are no longer only associated with 'accidents' resulting in damage or injury, but that there now seems to be a drive in the literature to study errors in a much broader context - not only across different sectors in the economy but also across different managerial

Requests for copies should be addressed to: K Stanz, Department of Human Resource Management, RAU University, PO Box 524, Auckland Park, 2006 functions. This tendency is also evident in the literature as far as empirical research is concerned. On the basis of Reason (1990) it appears that empirical studies progressed from covering the accident and safety field, the field of ergonomics, the engineering field as far as automated and semi-automated systems are concerned, to the current emphasis on managerial decisions.

As far as theoretical issues are concerned, an abundance of views, opinions, theories and research approaches regarding human error is to be found in the literature. From the literature it appears that those anchored in the man as information processor and the allied field of human cognition, are the most influential. In short these two approaches concentrate on the reception of information, decisions made on the basis of the information and the eventual execution of responses as the loci or sources of human error. Variations in the views of proponents in each of these two approaches seem to be mainly due to the factors (including attitudes), which may affect sound cognition or information processing.

The importance of attitudes (or its allied concepts such as world view, orientation and others) in the study of errors can be inferred from the present-day approach to management or organisational behaviour where values and culture are considered as primary factors in determining organisational success and survival. On the basis of the literature there is the temptation to suggest that value and attitude are concepts applicable to the individual and that value and culture are related concepts applicable to the organisation.

Errors have been defined as "... all those occasions in which a planned sequence of mental or physical activities fails to achieve its intended outcome, and when these cannot be attributed to the intervention of some change agency" (Reason, 1990, p. 9). Rasmussen (1986, p. 149) defined error in a much simpler way: "... if a system performs less satisfactory than it normally does because of human act or a disturbance that could have been counteracted by a reasonable human act - the cause will very likely be identified as a human error".

\section{Nature of errors}

According to Reason (1990) human error is neither as abundant nor as varied as its vast potential might suggest. Not only are errors much scarcer than correct actions, they also tend to take a surprisingly limited number of forms. Errors also appear in 
similar guises across a wide range of mental activities. Comparable error forms can be identified in action, speech, perception, recognition, judgement, problem solving, decisionmaking, concept formation, interpretation and the like (Rasmussen, 1982).

The exact representation of a typical framework for human error is not possible. Human error and human cognition is related and a typical description of the aspects of human cognition is not yet fully understood. Notwithstanding the differences between psychologists on these subjects regarding structure, processing and representation, Reason $(1988,1990)$ and Rasmussen (1986) indicated that most of the contemporary models contain important areas of common ground, which could be classified as control modes, cognitive structures, attentional mode and schematic control mode.

The accuracy of error prediction depends largely on the extent to which the factors giving rise to the errors are understood. This understanding requires a theory, which relates to the three major elements in the production of an error: (a) the nature of the task and its environmental circumstances, (b) the mechanisms governing performance and (c) the general nature of the individual (Reason, 1990).

The notion of intention and error is inseparable and intention comprises of two elements: (a) an expression of the end-state to be obtained, and (b) an indication of the means by which it is to be achieved. Both elements may vary widely in their degree of specificity (Reason, 1990). "All intentional actions have intentions in action but not all intentional actions have prior intentions" (Searle as cited by Reason, 1990, p. 6). A distinction between error types and error forms is also used to classify errors. Error type relates to the presumed origin of the error within the stages involved in conceiving and then carrying out an action sequence. The stages are described by Reason (1990) under three broad headings: planning, storage, and execution.

\section{Error theories}

The literature abounds to a number of taxonomies reflecting a variety of practical concerns and theoretical orientations and ranging from the highly task specific to broad statements of underlying error tendencies. The grouping of error theories could be done by means of the natural science tradition or the cognitive science tradition. The basic assumptions about human cognition form the bases of the modern error theories (Reason, 1990).

A number of models were developed in the theory on errors (Neisser,1976; Broadbent, 1984; Norman and Draper, 1986). The most practical model was the one developed by Rasmussen (1982) who developed the skill-ruleknowledge framework in an effort to construct an executable taxonomy of human errors. The framework defined three performance levels:

- Skill-based level $(S B)$. At this level human performance is governed by stored patterns of pre-programmed instructions. Errors at this level will be related to the intrinsic variability of force, space or time coordination.

- Rule-based level (RB). Solutions of familiar problems are governed by stored rules. Errors at this level are associated with the misclassification of situations leading to the application of the wrong rule or with the incorrect recall of procedures.

- Knowledge based level (KB). Actions must be planned on-line, using conscious analytical processes and previous gained knowledge or experience. Errors would therefore arise from resource limitations or incomplete or incorrect knowledge.

Rasmussen (1982) identified eight stages of decision-making (or problem solution): activation, observation, identification, interpretation, evaluation, goal selection, procedure selection and activation. The major contribution from this framework has been to chart the shortcuts that human decision makers take in real-life situations.

\section{Evaluation of errors}

The focus on the evaluation of errors is stressed for two main reasons. First, errors have been deeply investigated from different theoretical perspectives and in a number of environmental settings (Reason, 1990). It is thus possible to refer to data already collected and to consolidated theories to interpret and even to classify a given deviation from the correct course of action. Second, errors are worthwhile indicators signalling all those circumstances in which environmental characteristics do not match with cognitive abilities (Rizzo, Parlangeli, Marchigiani, \& Bagnara, 1996).

With few exceptions, error analyses address mainly the quantitative issue (Norman, 1983). These analyses cope with the number or the rate of errors that are produced in a given session of interaction, but leave to the research teams in charge for finding a solution for the different types of errors. The few approaches that have been devised to address the qualitative issue mainly focus on the occurrence of the error, not on its detection and recovery. They provide guidelines for reducing the occurrence of errors or for minimizing their impact but rarely for supporting their detection and recovery (Rizzo, et al., 1996).

One of the few set of guidelines that cope with the issue of error detection is the one put forward by Norman (1983). This set of principles has, however, some drawbacks that make the principles only partially applicable to all the types of human error. Indeed, the guidelines are applicable to 'slips' and rarely to 'mistakes' (Rizzo, et al., 1996).

\section{Error orientation}

Errors and attitudes are important issues in work psychology for a number of reasons. Errors produce stress, lead to accidents, influences quality outputs, has an effect on performance and will affect the culture of the organisation (van Dyck, 1997).

The attitudes towards errors and how one deal with them are indications of a company's organisational culture (Baron, 1986). Bureaucratic companies usually have the attitude to prevent errors from happening at all costs, while the entrepreneurial business usually have a more positive attitude towards error and what can be learnt from them (van Dyck, Frese and Sonnentag, 2000). If a company attempts to change its culture one needs a measure of error orientation (Van Dyck, 2000).

Rybowiak, Garst, Frese and Batinic (1999) found the main concepts of error orientation to be: (a) analysing error occurrences; (b) communication with colleagues; (c) short term competence error handling and recovery; (d) long term learning from errors; (e) anticipation of errors; and (f) adequate risk taking. Together these concepts enhance a successful error orientation approach. Error management is impeded by (g) strain caused by errors, and (h) the covering up of errors.

Rybowiak et al., (1999) developed one of the first questionnaires aimed at measuring the orientation towards errors - the Error Orientation Questionnaire (EOQ). The publication indicates that error orientation can be conceptualised within the general coping concept. According to this research team, the coping concept refers to the extent that an individual can stay calm in the face of errors, to cover up the fact that an error has occurred, as opposed to communicating about them, and to actively deal with an error or to learn from it.

In the development of the EOQ (Rybowiak, et al., 1999) a set of six scales - error competence, learning from error, error risk taking, error strain, error anticipation, covering up errors - for measuring orientation towards errors. From the items included 
in the scales, they suggest that error competence and learning from errors are related to self-efficacy, plan- and action orientation; error risk taking was related to need for achievement, control rejection and readiness for change; error strain was related to ill-health; error anticipation implied a negative outlook on life; and covering up was related both to environmental factors (career stress, job security) and to lack of self-esteem, rejecting responsibility and control.

According to the authors the strength of their study was the fact that they could cross-validate the factor structure and that the scales were developed in a representative sample.

Previous studies have indicated that an error culture does exist in companies (Rybowiak, Garst, Frese and Batinic 1999; Van Dyck, 2000). Van Dyck (2000) developed an Error Culture Questionnaire and concluded that beliefs, attitudes, norms and behavioural approaches regarding errors could be shared and that error culture does exist. The reaction of management toward errors could be placed in two basic categories punishment and empathy.

The replication and the function of exploratory behaviour, and the effect of training were researched. Dormann \& Frese, (1994) and Van Dyck, (2000) published results on the managing of error culture in organisations. Bear (1999) studied the influence of error management climate and psychological safety climate on the relationship between modern manufacturing practices and company performance. Other studies include error training and the role of goal orientation (Heimbeck, 1999), and the role of error culture on organisational performance (Van Dyck, et al., 2000).

\section{Attitudes}

Attitudes are a central part of human individuality. In most instances it is most certainly the case that a persons' attitude towards a particular attitude object may influence his or her behaviour towards this object. Moreover an attitude toward one object may influence behaviour (and attitudes) towards other attitude objects (Oppenheim, 1992). Attitudes are central to the subject of social psychology because they are central to social lives. Individuals are easily categorised according to their attitudes (e.g. conservatives or feminists).

An attitudes statement is "... a single sentence that expresses a point of view, a belief, a preference, a judgement, an emotional feeling, or a view on something" (Oppenheim, 1992, p. 11). Bohner and Wänke (2002) simply define an attitude as being a summary evaluation of an object of thought. Baron (1986, p. 140) defines attitudes as "... relatively lasting clusters of feelings, beliefs, and behaviour tendencies directed toward specific persons, ideas, objects or groups."

Attitudes could be developed through natural selection (Tesser, 1993) or through external influences which include exposure (Bornstein, 1989), contiguity, imitation, reinforcement, observation (Bohner \& Wänke, 2002) and persuasion (Howard, 1997).

\section{Attitude and behaviour}

Various indicators of attitude strength as well as personality variables have been identified as moderators of the attitudebehaviour relation (Bohner \& Wänke, 2002). High correlations though between attitude and behaviour do not provide sufficient evidence for inferring that attitude cause behaviour. Behaviour may influence attitude. Third variables such as salient context-dependent beliefs influence both attitude reports and behaviour. Schwartz and Bohner (2001) indicate that if these context factors remain stable, high attitude-behaviour correlations could be expected. Attitudes do predict behaviour but they do not cause behaviour.

Attitudes are mostly perceived as straight lines, running from positive, through neutral, to negative feelings about the object or issue in question. The general attempts at measurements are then to place a person's attitude on the linear continuum in such a way that it can be described as mildly positive, strongly negative and so on - preferably in terms of a numerical score or else by ranking (Oppenheim, 1992).

Attitudes will play an important role in the operations and management of a business. Work-related attitudes often play a key role in shaping the behaviour and actions in organisations. The understanding of attitudes of individuals will enhance the understanding of the people side of the business. The views individuals hold about their jobs and organisations often exert powerful effects upon their performance and other aspects of organisational behaviour. The most successful methods to change attitudes are based on approaches of persuasion and dissonance (Baron, 1986).

Key work-related attitudes that indicate the role attitudes can play in the business and management environment includes job satisfaction, organisational commitment, prejudice and dissonance.

On the basis of the importance attached to the role of attitudes, values and culture as far as errors are concerned, the main purpose of the study then was to develop a questionnaire through which the attitudes of managers towards errors can be measured.

The study addresses the issue of the attitudes of management towards errors and a questionnaire will be developed to measure this attitude.

\section{METHOD}

\section{Participants}

The sample was chosen from a variety of business sectors in South Africa. A basic database with potential companies was drawn up. No distinction was made in terms of the size of the company and the selection of businesses included large multinational corporations, public companies, private companies and individually owned businesses.

Managers at the level of middle management, senior management and at executive level were approached within the identified businesses to complete the questionnaire. It was expected that the respondent has some subordinates reporting to him/her or at least be in decision-making managerial position.

\section{Procedure}

A senior executive of the target companies was contacted and after receiving confirmation that the company could be approached for the research, the questionnaire was distributed through electronic mail to either a contact person in the company (who would further distribute it within the company) or to the contact list supplied by the company. The questionnaire was returned to a dedicated electronic mail address. In some cases hard copies of the questionnaire were distributed when requested.

It is difficult to determine an accurate response rate for electronically distributed questionnaires since the number of questionnaires forwarded from one participant to the next, can not be established. The researcher sent out 1386 questionnaires electronically to 283 businesses and 150 hard copies were distributed to individuals. In total 247 questionnaires were returned of which $85 \%$ were returned electronically. Of the 247 questionnaires that were returned, fifteen were discarded due to the incorrect completion thereof and 232 were statistically analysed. The composition of the population and sample is presented in Table 1 . The sector analysis indicate that the manufacturing environment dominated the sample as $25 \%$ of the participants came from this sector and none of the other sectors reaching more than $10 \%$ participation. 
TABLE 1

BIOgRAPHICAL PARTICULARS OF THE RESPONDENTS

\begin{tabular}{|c|c|c|}
\hline & \multicolumn{2}{|c|}{ Sample } \\
\hline & Number & Percentage \\
\hline \multicolumn{3}{|l|}{ Sector } \\
\hline Academic & 2 & 0,9 \\
\hline Agriculture & 13 & 5,6 \\
\hline Communication & 13 & 5,6 \\
\hline Construction & 9 & 3,9 \\
\hline Education & 9 & 3,9 \\
\hline Financial Services & 19 & 8,2 \\
\hline Government & 4 & 1,7 \\
\hline Information Technology & 17 & 7,3 \\
\hline Manufacturing & 59 & 25,4 \\
\hline Mining & 3 & 1,3 \\
\hline Retail & 16 & 6,9 \\
\hline Service Provider & 23 & 9,9 \\
\hline Social Services & 2 & 0,9 \\
\hline Transport & 22 & 9,4 \\
\hline Other & 21 & 9,1 \\
\hline Total & 232 & 100,0 \\
\hline \multicolumn{3}{|l|}{ Number of Employees } \\
\hline$<50$ & 101 & 43,5 \\
\hline $51-200$ & 40 & 17,2 \\
\hline $201-1000$ & 47 & 20,3 \\
\hline$>1000$ & 44 & 19,0 \\
\hline Total & 232 & 100,0 \\
\hline \multicolumn{3}{|l|}{ Business Turnover } \\
\hline$<\mathrm{R} 10 \mathrm{~m}$ & 60 & 25,9 \\
\hline $\mathrm{R} 10 \mathrm{~m}-\mathrm{R} 50 \mathrm{~m}$ & 50 & 21,6 \\
\hline $\mathrm{R} 50 \mathrm{~m}-\mathrm{R} 100 \mathrm{~m}$ & 21 & 9,0 \\
\hline $\mathrm{R} 100 \mathrm{~m}-\mathrm{R} 500 \mathrm{~m}$ & 43 & 18,5 \\
\hline$>\mathrm{R} 500 \mathrm{~m}$ & 45 & 19,4 \\
\hline No Turnover & 13 & 5,6 \\
\hline Total & 232 & 100,0 \\
\hline \multicolumn{3}{|l|}{ Management level } \\
\hline Owner & 22 & 9,5 \\
\hline Director & 31 & 13,3 \\
\hline Senior Manager & 84 & 36,2 \\
\hline Middle Manager & 63 & 27,2 \\
\hline Junior Manager & 19 & 8,2 \\
\hline Other & 13 & 5,6 \\
\hline Total & 232 & 100,0 \\
\hline \multicolumn{3}{|l|}{ Academic Qualifications } \\
\hline Grade 12 and lower & 26 & 11,2 \\
\hline Degree/Diploma & 101 & 43,6 \\
\hline Post Graduate & 105 & 45,2 \\
\hline Total & 232 & 100,0 \\
\hline \multicolumn{3}{|l|}{ Gender } \\
\hline Male & 174 & 75,0 \\
\hline Female & 58 & 25,0 \\
\hline Total & 232 & 100,0 \\
\hline \multicolumn{3}{|l|}{ Age } \\
\hline$<35$ & 64 & 28,4 \\
\hline $36-45$ & 100 & 44,5 \\
\hline$>45$ & 61 & 27,1 \\
\hline Total & 225 & 100,0 \\
\hline
\end{tabular}

From Table 1 it can be seen that the majority of the participants are general managers from the senior management level and that they have a tertiary qualification, are male and in the age group 36 to 45 .

\section{The Measuring Instrument}

The questionnaire developed in this study consists of two sections - a biographical section and the Management Error Orientation Questionnaire (MEOQ). The Management Error Orientation Questionnaire (MEOQ) builds on research of individual error management orientation (Rybowiak et al., 1999).
The MEOQ consists of 59 items, which were developed within eleven theoretical attitude factors related directly to the management of errors. These factors are error competence, learning from errors, error risk taking, error strain, error anticipation, covering up errors, error communication, thinking about errors, helping with errors, prevention of errors and general attitude towards error The first six of these categories were taken from the Error Orientation Questionnaire (EOQ) that was developed by Rybowiak et al. (1999). Each category has a minimum of four questions.

All items in the MEOQ are endorsed on a five point Likert scale ranging from 1 (strongly disagree) to 5 (strongly agree).

\section{Statistical analysis}

The factor analysis on item scores was conducted by the Statistical Consultation Service of the Rand Afrikaans University according to a procedure suggested by Schepers (1992).

\section{RESULTS}

\section{Factor analysis of items}

The 59 items of the MEOQ were intercorrelated and subjected to a principal factor analysis. Due to a lack of space, the intercorrelation matrix is not reproduced here.

Based on Kaiser's criterion (1961), 13 factors were postulated and extracted. The obtained factor matrix was rotated to simple structure by means of a Varimax rotation.

Subscores were calculated in respect of 12 factors with acceptable loadings. Five items were omitted during the initial factor analysis.

\section{Factor analysis of the subscores of the MEOQ}

The 12 subscores were intercorrelated and subjected to a principal factor analysis. The obtained factor matrix was rotated to simple structure by means of a Direct Oblimin rotation. The intercorrelations of the subscores are given in Table 2 .

Three factors were postulated and extracted. The three factors accounted for $51,97 \%$ of the variance of the test scores. The eigenvalues are presented in Table 3.

Table 3 indicates that three eigenvalues are greater than unity. Table 4 shows the rotated factor matrix of the MEOQ. From an inspection of Table 4 it appears that all three factors are relatively well determined. Factor I has six moderate to high loadings and Factor II and III have three loadings each. The intercorrelations between the three factors are given in Table 5. Two items were omitted during the second-order factor analysis. Table 5 shows that Factor II (the risk of errors) and Factor III (error strain) is positively correlated.

Three scales were formed corresponding to the three factors by including all the items with high loadings on each factor. An item analysis was performed in respect of Scale I with 37 items (Table 6), Scale II with 6 items (Table 7) and Scale III with 9 items (Table 8) and Cronbach alpha coefficients of 0,$937 ; 0,701$ and 0,717 respectively were found.

Table 6 shows that in Scale I the item-total correlations range from 0,118 to 0,812 . The scale is internally relatively inconsistent and no items were rejected. The high reliability coefficient was sufficient for the purpose of constructing a MEOQ. 
TABLE 2

THE MATRIX OF INTERCORRELATIONS OF SIMPLIFIED FACTOR SCORES

\begin{tabular}{|c|c|c|c|c|c|c|c|c|c|c|c|c|}
\hline \multicolumn{13}{|c|}{ SIMPLIFIED FACTOR SCORE } \\
\hline $\begin{array}{l}\text { SIMPLIFIED } \\
\text { FACTOR } \\
\text { SCORE }\end{array}$ & D 1 & 2 & 3 & 4 & 5 & 6 & 7 & 8 & 9 & 10 & 11 & 12 \\
\hline 1 & 1,000 & & & & & & & & & & & \\
\hline 2 & $-0,252$ & 1,000 & & & & & & & & & & \\
\hline 3 & 0,125 & 0,304 & 1,000 & & & & & & & & & \\
\hline 4 & 0,379 & $-0,271$ & $-0,116$ & 1,000 & & & & & & & & \\
\hline 5 & 0,544 & 0,076 & 0,200 & 0,052 & 1,000 & & & & & & & \\
\hline 6 & 0,261 & $-0,182$ & $-0,041$ & 0,383 & 0,220 & 1,000 & & & & & & \\
\hline 7 & $-0,426$ & 0,352 & 0,049 & $-0,142$ & $-0,115$ & $-0,118$ & 1,000 & & & & & \\
\hline 8 & 0,042 & $-0,152$ & $-0,224$ & 0,382 & $-0,047$ & 0,234 & 0,042 & 1,000 & & & & \\
\hline 9 & 0,294 & 0,031 & 0,141 & 0,156 & 0,317 & 0,285 & 0,014 & 0,031 & 1,000 & & & \\
\hline 10 & $-0,247$ & 0,180 & $-0,045$ & $-0,012$ & $-0,122$ & $-0,159$ & 0,211 & 0,016 & $-0,071$ & 1,000 & & \\
\hline 11 & 0,424 & $-0,037$ & 0,159 & 0,167 & 0,287 & 0,163 & $-0,085$ & 0,004 & 0,185 & $-0,212$ & 1,000 & \\
\hline 12 & 0,442 & $-0,110$ & $-0,026$ & 0,269 & 0,297 & 0,242 & $-0,122$ & 0,111 & 0,278 & $-0,59$ & 0,275 & 1,000 \\
\hline
\end{tabular}

TABLE 3

EIGENVALUES OF UNREDUCED INTERCORRELATION MATRIX

\begin{tabular}{lccc}
\hline Root & $\begin{array}{c}\text { Eigenvalues } \\
\text { Variance }\end{array}$ & $\begin{array}{c}\% \text { of } \\
\%\end{array}$ & Cumulative \\
\hline 1 & 3,027 & 25,226 & 25,228 \\
2 & 1,830 & 15,252 & 40,480 \\
3 & 1,379 & 11,492 & 51,972 \\
4 & 0,927 & 7,728 & 59,700 \\
5 & 0,843 & 7,027 & 66,727 \\
6 & 0,797 & 6,644 & 73,371 \\
7 & 0,689 & 5,744 & 79,115 \\
8 & 0,621 & 5,176 & 84,291 \\
9 & 0,605 & 5,041 & 89,332 \\
10 & 0,525 & 4,375 & 93,707 \\
11 & 0,500 & 4,169 & 97,876 \\
12 & 0,255 & 2,124 & 100,000 \\
Trace & 12,000 & & \\
\hline
\end{tabular}

TABLE 4

ROTATED FACTOR MATRIX OF THE MEOQ

\begin{tabular}{lllllll}
\hline Variables & Items & K & Factor I & Factor II & Factor III & $\mathbf{h}_{\text {J }}^{2}$ \\
\hline SFS1 & $\begin{array}{l}41,52,40,29,33,22, \\
\text { 16, } 1,54,30,45,28,\end{array}$ & 0,651 & $-0,048$ & $-0,505$ & 0,821 \\
& $\begin{array}{l}51,12,14,8,27,57, \\
\end{array}$ & & & & & \\
& $46,53,38,59,3,11,7$, & & & & \\
SFS2 & $49,4,56,39,36,5$ & 6 & 0,230 & $-0,064$ & 0,305 & 0,501 \\
SFS3 & $43,13,32,31,44,48$ & 6 & 0,371 & 0,342 & 0,144 & 0,258 \\
SFS4 & $20,23,47$ & 3 & 0,192 & $-0,630$ & $-0,087$ & 0,488 \\
SFS5 & 58,9 & 2 & 0,655 & 0,102 & $-0,059$ & 0,446 \\
SFS6 & 37 & 1 & 0,306 & $-0,419$ & $-0,040$ & 0,301 \\
SFS7 & 19,25 & 2 & $-0,011$ & $-0,066$ & 0,645 & 0,405 \\
SFS8 & 55,35 & 2 & $-0,033$ & $-0,600$ & 0,109 & 0,344 \\
SFS9 & 18 & 1 & 0,500 & $-0,134$ & 0,117 & 0,262 \\
SFS10 & 50 & 1 & $-0,136$ & $-0,064$ & 0,305 & 0,122 \\
SFS11 & 42 & 1 & 0,453 & $-0,055$ & $-0,121$ & 0,241 \\
SFS12 & 26 & 1 & 0,433 & $-0,233$ & $-0,088$ & 0,287 \\
\hline & & 52 & 37 & 6 & 9 & \\
\hline
\end{tabular}

TABLE 5 MATRIX OF INTERCORRELATION OF ROTATED FACTORS

\begin{tabular}{lccc}
\hline & Factor I & Factor II & Factor III \\
\hline Factor I & 1,000 & & \\
Factor II & $-0,007$ & 1,000 & \\
Factor III & $-0,191$ & 0,212 & 1,000 \\
\hline
\end{tabular}

In Scale II the item-total correlations range from 0,275 to 0,622 and although internally consistent and no items were rejected, there were only six items in this scale and the reliability coefficient was just above the standard of 0,7 . The scale does fit the purpose of constructing the MEOQ and was retained. The obtained reliability for Scale III was 0,717. The item-total correlations varied from 0,224 to 0,464 , which indicate internal consistency. No items were lost and the scale comprises nine items. 
TABLE 6

ITEM STATISTICS OF SCALE I: THE ATTITUDE OF DEALING WITH ERORS

\begin{tabular}{|c|c|c|c|c|c|c|}
\hline Item & Description & $\mathbf{N}$ & $\left(X_{g}\right)$ & $\left(s_{g}\right)$ & $\left(r_{g x}\right)$ & $\left(\mathbf{r}_{\mathrm{gx}} \mathbf{s}_{\mathrm{g}}\right)$ \\
\hline Q1 & When an error occurs, management at this organisation usually knows how to rectify it & 226 & 3,735 & 1,042 & 0,637 & 0,664 \\
\hline Q3 & In our organisation management take into account that errors will be made from time to time & 226 & 3,628 & 1,039 & 0,434 & 0,451 \\
\hline Q7* & In our organisation errors will not be admitted if it has not been detected & 226 & 3,080 & 1,201 & 0,393 & 0,472 \\
\hline Q8 & $\begin{array}{l}\text { In our organisation, when someone makes an error, s/he shares it with others so that the } \\
\text { same mistake won't be made again }\end{array}$ & 226 & 3,115 & 1,172 & 0,602 & 0,706 \\
\hline Q9 & In this organisation, management spends a lot of time on how errors could have been prevented & 226 & 2,885 & 1,277 & 0,513 & 0,655 \\
\hline Q11 & It is a goal of management in this organisation that work gets done without errors & 226 & 4,066 & 0,984 & 0,472 & 0,465 \\
\hline Q12 & Management in our organisation are directly involved in the correction of errors & 226 & 3,611 & 1,111 & 0,610 & 0,678 \\
\hline Q13 & For an organisation to survive it is essential to work without errors & 226 & 3,027 & 1,286 & 0,282 & 0,363 \\
\hline Q14 & $\begin{array}{l}\text { When employees in our organisation make an error, they can ask others for advice on } \\
\text { how to continue }\end{array}$ & 226 & 3,925 & 1,006 & 0,641 & 0,645 \\
\hline Q16 & Management believes that the open discussion of errors is fruitful & 226 & 3,863 & 1,152 & 0,704 & 0,811 \\
\hline Q17 & In this organisation management will discipline those covering up mistakes & 226 & 3,677 & 1,157 & 0,337 & 0,390 \\
\hline Q18 & Management plan for mistakes to happen in our business & 226 & 2,726 & 1,114 & 0,312 & 0,348 \\
\hline Q22 & Quick and efficient correction of errors has a high priority in this organisation & 226 & 3,991 & 1,112 & 0,725 & 0,806 \\
\hline Q26 & $\begin{array}{l}\text { When people start to work on a new task in this organisation, they are aware that errors } \\
\text { can occur }\end{array}$ & 226 & 3,686 & 0,949 & 0,443 & 0,420 \\
\hline Q27* & In this organisation the discussion of errors with others serves no point & 226 & 3,951 & 1,201 & 0,605 & 0,727 \\
\hline Q28 & In general management in this organisation warn each other about errors that might come up & 226 & 3,535 & 1,075 & 0,637 & 0,685 \\
\hline Q29 & After an error, management thinks through how to correct it & 226 & 3,854 & 0,980 & 0,769 & 0,754 \\
\hline Q30 & When individuals in our organisation are unable to correct an error they turn to management & 226 & 3,858 & 0,908 & 0,599 & 0,544 \\
\hline Q31 & Management believe work can be done without error if enough effort is put into it & 226 & 3,535 & 0,980 & 0,172 & 0,169 \\
\hline Q32 & People who make errors should be disciplined & 226 & 2,420 & 1,126 & 0,178 & 0,2004 \\
\hline Q33 & In our organisation, errors are promptly corrected & 226 & 3,615 & 1,115 & 0,760 & 0,847 \\
\hline Q38* & The discussion of errors between managers in our organisation has limited purpose & 226 & 3,739 & 1,115 & 0,530 & 0,591 \\
\hline Q40 & $\begin{array}{l}\text { Since errors and their solutions provide important information for our work, we discuss } \\
\text { them within our organisation }\end{array}$ & 226 & 3,633 & 1,051 & 0,786 & 0,826 \\
\hline Q41 & In our organisation the occurrence of an error, is analysed thoroughly & 226 & 3,443 & 1,173 & 0,812 & 0,952 \\
\hline Q42 & $\begin{array}{l}\text { If people in our organisation are unable to continue their work after an error, they can } \\
\text { rely on others to complete the task }\end{array}$ & 226 & 3,212 & 1,115 & 0,420 & 0,468 \\
\hline Q43 & Making errors is unnecessary & 226 & 2,960 & 1,259 & 0,206 & 0,259 \\
\hline Q44* & Most errors happen due to incapable workers & 226 & 3,562 & 1,119 & 0,118 & 0,132 \\
\hline Q45 & Although mistakes are made in our organisation, we don't let go of the final goal & 226 & 4,248 & 0,806 & 0,575 & 0,464 \\
\hline Q46 & Management in this organisation believes that errors point to areas of improvement & 226 & 3,805 & 0,974 & 0,596 & 0,581 \\
\hline Q48 & Management in our organisation gets upset when errors occur & 226 & 3,504 & 1,003 & 0,099 & 0,099 \\
\hline Q51 & Management in this organisation discuss errors among one another & 226 & 3,566 & 1,032 & 0.670 & 0,691 \\
\hline Q52 & If something went wrong, sufficient time is taken in our organisation to think it through & 226 & 3,274 & 1,101 & 0,789 & 0,869 \\
\hline Q53 & Error management is part of the strategic thoughts of our business & 226 & 2,956 & 1,232 & 0,654 & 0,806 \\
\hline Q54 & Management organises work in such a way that the correction of errors will be as easy as possible & 226 & 3,230 & 1,135 & 0,724 & 0,822 \\
\hline Q57* & Management prefer to keep their errors to themselves & 226 & 3,217 & 1,201 & 0,520 & 0,625 \\
\hline Q58 & Management are focussing on the possibility of errors happening & 226 & 2,850 & 0,995 & 0,501 & 0,499 \\
\hline Q59* & In our organisation employees that admit errors are asking for trouble & 226 & 3,730 & 1,201 & 0,520 & 0,625 \\
\hline
\end{tabular}

$\left(\mathrm{r}_{\mathrm{gx}} \mathrm{s}_{\mathrm{g}}\right) \quad$ Index of Reliability of item $\mathrm{g}$

$\left(\mathrm{r}_{\mathrm{gx}}\right) \quad$ correlation of Item $\mathrm{g}$ with total score

$\left(\mathrm{s}_{\mathrm{g}}\right) \quad$ Standard Deviation of the item $\mathrm{g}$

$\left(\mathrm{X}_{\mathrm{g}}\right) \quad$ Mean of the item

Cronbach Alpha

Number of item

Means of items

Standard Deviation of mean of items $\quad=0,421$

* Inverse items

\section{DISCUSSION}

The 59 items written for the MEOQ were subjected to a factor analysis and the results obtained in the present study yielded three factors. The three factors that emerged were identified as Factor I: The Attitude of dealing with errors, Factor II: The Risk of Errors and Factor III: Error Strain (stressed caused by errors).

A content analysis of the theoretical categories indicate that more items would have been lost (26 against 7) if the original theoretical design would have been used as the MEOQ. In the exploratory factor analysis one of the final factors that was formed (Factor III), was named Error Stain and in the content analysis the factor error strain with 9 items were eliminated.

The Attitude of dealing with errors can be said to represent aspects like competency in dealing with errors, the communication of errors, the prevention of errors, thinking about errors, helping with errors and general attitude about errors. This factor relates to the practical aspects of error management.

The Risk of Errors is an indication of the effect that errors could have on the business and is specifically related to management. This factor addresses risk management and 
TABLE 7

FACTOR SCALE II (STRESS CAUSED BY ERROR): DESCRIPTIVE STATISTICS

\begin{tabular}{|c|c|c|c|c|c|c|}
\hline Item & Description & $\mathbf{N}$ & $\left(\mathrm{X}_{\mathrm{g}}\right)$ & $\left(s_{g}\right)$ & $\left(\mathbf{r}_{\mathrm{gx}}\right)$ & $\left(r_{g x} s_{g}\right)$ \\
\hline Q20 & Management in this company encourages taking calculated risks & 228 & 3,009 & 1,172 & 0,431 & 0,505 \\
\hline Q23 & $\begin{array}{l}\text { Management in our organisation has the view that they would rather make mistakes } \\
\text { than to do nothing }\end{array}$ & 228 & 3,224 & 1,220 & 0,505 & 0,616 \\
\hline Q35 & For the organisations to achieve something, it has to risk the occurrence of errors & 228 & 3,746 & 1,097 & 0,275 & 0,302 \\
\hline Q37 & Management are not surprised by mistakes because they expect them & 228 & 2,860 & 1,027 & 0,382 & 0,392 \\
\hline Q47 & Management believes that it is fine to risk an error every once in a while & 228 & 3,026 & 1,090 & 0,622 & 0,678 \\
\hline Q55 & To get better in what we do in our business, we don't mind that something could go wrong & 228 & 2,973 & 1,009 & 0,331 & 0,334 \\
\hline
\end{tabular}

$\left(\mathrm{r}_{\mathrm{gx}} \mathrm{s}_{\mathrm{g}}\right) \quad$ Index of Reliability of item $\mathrm{g}$

$\left(\mathrm{r}_{\mathrm{gx}}\right) \quad$ correlation of Item g with total score

$\left(\mathrm{s}_{\mathrm{g}}\right) \quad$ Standard Deviation of the item $\mathrm{g}$

$\left(\mathrm{X}_{\mathrm{g}}\right) \quad$ Mean of the item

Number of items

Means of items

$\begin{aligned} & =3,140 \\ \text { Standard Deviation of mean of items } & =0,320\end{aligned}$

TABLe 8

FACTOR SCALE III (THE RISK OF MAKING ERRORS): DESCRIPTIVE STATISTICS

\begin{tabular}{|c|c|c|c|c|c|c|}
\hline Item & Description & $\mathbf{N}$ & $\left(\mathrm{X}_{\mathrm{g}}\right)$ & $\left(s_{g}\right)$ & $\left(r_{g x}\right)$ & $\left(r_{g x} s_{g}\right)$ \\
\hline Q4 & Management in our organisation feel stressed when errors happen & 229 & 3,572 & 1,047 & 0,402 & 0,421 \\
\hline Q5 & During their work people at this organisation are often concerned that errors might occur & 229 & 3,319 & 1,030 & 0,255 & 0,263 \\
\hline Q19 & $\begin{array}{l}\text { Employees in this organisations are often relieved if someone other than they themselves } \\
\text { makes an error }\end{array}$ & 229 & 3,044 & 1,173 & 0,416 & 0,488 \\
\hline Q25 & Management in this organisation are relieved if an error occurs in another department & 229 & 2,552 & 1,240 & 0,400 & 0,496 \\
\hline Q36 & Management in our organisation are afraid of mistakes happening & 229 & 3,044 & 1,154 & 0,464 & 0,536 \\
\hline Q39 & Announcing errors that you have made to others will have a negative effect on your career & 229 & 2,432 & 1,203 & 0,485 & 0,583 \\
\hline Q49 & In this organisation, management are often surprised when mistakes occur & 229 & 2,756 & 0,960 & 0,400 & 0,384 \\
\hline Q50 & There are advantages in covering up errors & 229 & 1,611 & 0,938 & 0,224 & 0,210 \\
\hline Q56 & In this organisation management gets irritated when errors occur & 229 & 3,288 & 1,086 & 0,458 & 0,497 \\
\hline
\end{tabular}

$\left(\mathrm{r}_{\mathrm{gx}} \mathrm{s}_{\mathrm{g}}\right) \quad$ Index of Reliability of item $\mathrm{g}$

$\left(\mathrm{r}_{\mathrm{gx}}\right) \quad$ correlation of Item $\mathrm{g}$ with total score

$\left(\mathrm{s}_{\mathrm{g}}\right) \quad$ Standard Deviation of the item $\mathrm{g}$

$\left(\mathrm{X}_{\mathrm{g}}\right) \quad$ Mean of the item

Number of items

Means of items

Standard Deviation of mean of items

could be preventative of nature. Error strain (Factor III) is related to the stress that is caused by errors happening or the possibility of errors happening. On the surface it appears that there is a connection between Risk of Errors and Error Strain with a positive correlation between these factors. The Attitude of dealing with errors will be preventative in nature and the Risk of Error and Error Strain relates to attitudes once the error has happened.

The results of this study cannot be compared to other similar research. Rybowiak et al. (1999) developed the EOQ with which the orientation of individuals in terms of errors was tested. Their study indicated six constructs in the empirical model of the EOQ and the results of the present study supported the reliabilities that were found in relation of the EOQ. Although differently worded, the three scales that were found to be reliable in the MEOQ also correlated well in the EOQ. It was found in the MEOQ that the cross-validation of the eight empirical groupings that were originally used in EOQ, was not reliable and that only two of those theoretical factors of the EOQ would have correlated well with the final factors of the MEOQ if they were to be used in the MEOQ. As the three scales found in the MEOQ were done through exploratory factor analysis, and the final questionnaire included most of the questions that were used in the EOQ it is concluded that the exploratory scales of the MEOQ carries more weight than the scales in the EOQ. It was also concluded that error orientation differs between individuals (as was tested in the EOQ) and managers (as was tested in the MEOQ) and that different factors determine the attitude between individuals and managers.

In practical terms the MEOQ could be used when new managers are appointed, in career contingency plans, in the development of a management team and when individuals are being promoted in the corporate hierarchy. The instrument could be used in the strategic planning process of a company to determine level of error orientation as an important internal factor and could indicate whether it is a strong point or weak point within the organisation.

In conclusion, the present study opens up new research possibilities, for instance the determination of management orientation among gender groups and in the South African context among different race groups. The testing of management attitudes in high-risk business sectors should further be determined. 


\section{REFERENCES}

Baron, R.A. (1986). Behaviour in organisations, $2^{\text {nd }}$ Ed. Borton: Allyn and Bacon Inc.

Bear, M. (1999). The influence of error management climate, and psychological safety climate on the relationship between modern manufacturing practices and company performance. Unpublished Master's thesis, University of Giessen, Giessen.

Bohner, G and Wänke, M. (2002). Attitude and Attitude Change. New York: Psychology Press.

Bornstein, R.F. (1989). Exposure and effect: Overview and metaanalyses of research, 1968-1987. Psychological Bulletin, 106, 265-289.

Broadbent, D.E. (1984). The Maltese Cross: A new simplistic model for memory. The Behavioral and Brain Sciences, 7, 55-94.

Dormann, T. and Frese, M. (1994). Error training: Replication and the function of exploratory behavior. International Journal of Human-Computer Interaction, 6, 365-372.

Heimbeck, D. (1999). Error training and the role of goal orientation. In Training and Motivation: The Function of Implementation Intentions, Goal Orientation and Errors for Performance. Doctoral dissertation, University of Amsterdam, Amsterdam.

Howard, D.J. (1997). Familiar phrases as peripheral persuasion cues. Journal of Experimental Social Psychology, 33, 231-243.

Huysamen, C.A. (2002). Behavioural and personality correlations in transactional and transformational leadership. Unpublished Doctor's dissertation. Johannesburg: Rand Afrikaans University.

Neisser, U. (1976). Cognition and reality: Principles and Implications of cognitive psychology. San Francisco: W.H. Freeman \& Co.

Norman, D.A. (1986). Reflections on cognition and parallel distributed processing. In D. Rummelhart and J. McClelland (Eds.), Parallel Distributed Processing (vol 2). Cambridge: MIT Press.

Norman, D.A. (1983). Design rules based on analysis of human error. Communications of the ACM, 26, 254-258.
Oppenheim, A.M. (1992). Questionnaire Design, Interviewing and Attitude Measurement. London: Printer Publishers.

Rasmussen, J. (1982). Human Errors: A Taxonomy for describing human malfunction in industrial installations. Journal of Occupational Accidents. 1982, 4, 311-335.

Rasmussen, J. (1986). Information processing and human-machine interaction. Amsterdam: Elsevier Science Publishers B.V.

Reason, J. (1988). Modelling the basic error tendencies of human operators. Reliability Engineering and System Safety, $22,137-153$

Reason, J. (1990). Human Error. Cambridge: Cambridge University Press.

Rizzo, A., Parlangeli, O, Marchigiani, E. and Bagnara, S. (1996) The Management of Human Errors in User-Centered Design. SIGCHI Bulletin, 28 (3), 6-10.

Rybowiak, V., Garst, H., Frese, M. and Batinic, B. (1999). Error Orientation Questionnarie (EOQ): reliability, validity, and different language equivalence. Journal of Organizational Behavior, 20 527-547.

Schepers, J.M. (1992). Toetskonstruksie: Teorie en praktyk. Johannesburg: RAU Press.

Schwartz, N. and Bohner, G. (2001). The construction of attitudes. In A. Tesser \& $\mathrm{N}$ Schwartz (Eds.), Blackwell handbook of social psychology: Vol. 1. Intra-individual processes (p 436-457). Oxford: Blackwell.

Tesser, A. (1993). The importance of heritability in psychological research: The case of attitudes. Psychological Review, 100, 129-142.

Van Dyck. C. (1997). Error climate and management issues: Its links to organizational performance. In $\mathrm{R}$ Pepermans, $\mathrm{A}$ Buelens, C.J. Vinkenburg \& P.G.W. Jansen (Eds), Managerial Behaviour and Practices. Amersfoort: Acco Publishers.

Van Dyck, C. (2000). Putting error to good use: Error management culture in organizations. Unpublished Doctoral dissertation, The Vrije Universiteit, Amsterdam, The Netherlands.

Van Dyck, C., Frese, M. and Sonnentag, S. (2000). Error management culture and organizational performance: On mastering the challenges of errors. Article submitted for publication. 